\title{
Glaciological characteristics of the ablation zone of Baltoro glacier, Karakoram, Pakistan
}

\author{
C. MAYER, ${ }^{1}$ A. LAMBRECHT, ${ }^{2}$ M. BELÒ, ${ }^{3}$ C. SMIRAGLIA, ${ }^{3}$ G. DIOLAIUTI ${ }^{3}$ \\ ${ }^{1}$ Commission for Glaciology, Bavarian Academy of Sciences, Alfons-Goppel Strasse 11, D-80539 Munich, Germany \\ E-mail: christoph.mayer@Irz.badw-munich.de \\ ${ }^{2}$ Institute for Meteorology and Geophysics, University of Innsbruck, Innrain 52, A-6020 Innsbruck, Austria \\ ${ }^{3}$ Department of Earth Sciences, University of Milan, Via Mangiagalli 34, I-20133 Milan, Italy
}

\begin{abstract}
Baltoro glacier in the Karakoram, Pakistan, is one of the world's largest valley glaciers. It drains an area of about $1500 \mathrm{~km}^{2}$ and is $>60 \mathrm{~km}$ long. In 2004 an Italian/German expedition carried out a glaciological field program on the ablation zone of the glacier, focusing on the ablation conditions and the dynamic state of the glacier. As Baltoro glacier is a debris-covered glacier, ice ablation also depends on the debris properties. Stake measurements of ice ablation and debris cover in combination with meteorological data from automatic weather stations close by have been used to determine the local melt conditions. Results from these calculations have been combined with an analysis of different classes of surface cover and information about precipitation, using remote-sensing techniques, in order to calculate mass fluxes for the upper part of Baltoro glacier. The dynamic state of the glacier has been investigated by GPS-based surface velocity measurements along the stake network. A comparison of these short-term measurements during the melt season with surface velocities computed from feature tracking of satellite images shows a high seasonal variability of the ice motion. We have shown that this variability is up to $100 \%$ of the annual mean velocity. On the basis of these investigations, the mass fluxes at the Concordia cross-section have been quantified. This approach can now be used together with the ablation calculations to reconstruct the variability of glacier extent and volume in the past using available climate data from the central Karakoram. From the comparison of historical measurements and photographs it is shown that the snout of Baltoro glacier is oscillating back and forth a couple of hundred metres. Otherwise it seems not to react with the same magnitude as other glaciers to the climatic change. Elevation changes at Concordia are a few tens of metres at the most.
\end{abstract}

\section{INTRODUCTION}

Water availability, especially during the dry season, will be an increasing problem in the semi-arid countries of central Asia, including Pakistan. Increasing population, higher living standards and an intensified agriculture will increase water consumption considerably. The glaciers of central Asia contribute significantly to the stream-flow, especially during the dry season (Konovalov, 1997; Hagg and Braun, 2005). The Karakoram Range in northern Pakistan and adjacent India and China is one of the main glacierized areas of the region, together with the Pamirs and Tien Shan. Some of the largest valley glaciers in the world can be found there (Wissmann, 1959), culminating in the aggregation of four of the longest glaciers in Asia around the K2 and Gasherbrum groups: Biafo, Siachen, Sarpo Laggo and Baltoro.

Although a large part of the population of northern Pakistan depends on meltwater from the Karakoram glaciers, only a few research projects have dealt intensively with these areas (e.g. Desio and others 1961; Batura Glacier Investigation Group, 1979; Hewitt and others, 1989). On the 50th anniversary of the first ascent of $\mathrm{K} 2$, the second highest mountain in the world, a group of Italian and German scientists conducted fieldwork on Baltoro glacier during June and July 2004. The field measurements focused on the geometry and morphology of the glacier, its dynamic state and the ablation conditions. The combined analysis of these measurements will provide important information on the current state of Baltoro glacier, the meltwater production and the mass budget. Special attention was given to the ice ablation in the debris-covered areas of the glacier (Mihalcea and others, 2006). Due to the recession of mountain glaciers worldwide, the fraction of debris cover in the ablation zone is increasing almost everywhere (Diolaiuti and others, 2003a). Thus, understanding the ablation processes for different debris-cover thickness and extent is of increasing importance.

The field data have been supplemented by remotesensing imagery, allowing us to extrapolate the point information on the glacier surface. In this way it is possible to estimate mass fluxes for different gates across the glacier. One of these gates has been used for our analysis. All the available geographic data have been integrated in a Geographic Information System (GIS), whose cartographic basis is the Baltoro map of Miyamori (2000). In addition, an attempt has been made to investigate the temporal evolution by comparing historical photographs and maps with recent images and our measurements.

\section{FIELD MEASUREMENTS}

Apart from exploration teams and mountaineers, Baltoro glacier has received little attention in the way of glaciological investigations (Dainelli and Marinelli, 1928; Spoleto, 1930; Desio and others, 1961; Ding, 1992). In the present work, the ablation conditions, especially of the debriscovered part, the mass transport and the dynamic state of Baltoro glacier have been investigated in an extensive field experiment (Fig. 1). 


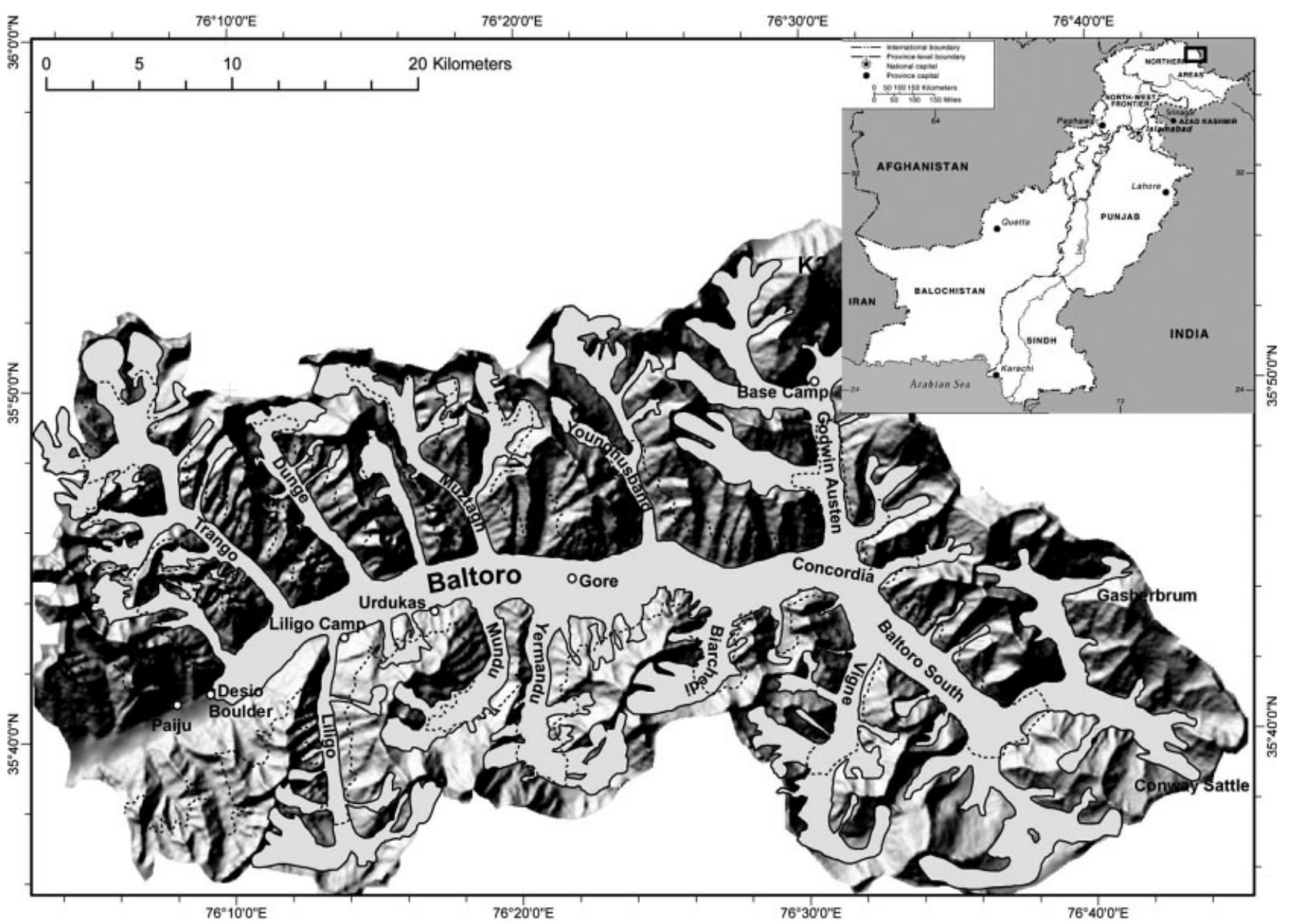

Fig. 1. Overview of the Baltoro drainage basin and the location of Baltoro glacier in Pakistan. The glacier as classified in this paper is shown in grey on the background of the shaded digital elevation model. The main locations and glaciers are shown on the map. The $5000 \mathrm{~m}$ contour line is displayed as a dashed line.

Two weather stations have been installed at Urdukas (4200 ma.s.l.) and K2 base camp (5100 ma.s.l.), respectively, in order to have a record of the meteorological parameters on the glacier and for the ice-free region (Mihalcea and others, 2006). The main recorded parameters are temperature, humidity, wind speed and radiation.

A network of stakes has been drilled on the glacier, starting at Urdukas (glacier surface elevation $4100 \mathrm{~m}$ ) and continuing upstream to an elevation of about $4800 \mathrm{~m}$ on both Godwin Austen Glacier and Baltoro south (Fig. 2). Inclusion of the tributaries downstream of Concordia has not been considered because of the complexity of the glacier network. At the stakes, surface elevation, ice velocity and ablation have been measured for different time periods, depending on the date of installation and the date of the second visit. At some stakes, thermistors at different depths in the debris cover recorded the temperature at a sampling interval of $5 \mathrm{~min}$. In addition to the longitudinal profile, cross-profiles at Urdukas, Gore I (4300 m), Concordia $(4600 \mathrm{~m})$, Godwin Austen $(4800 \mathrm{~m})$ and Baltoro south $(4700 \mathrm{~m})$ enable the estimation of velocity variations across the glacier. The topography of the cross-profiles has also been measured with high resolution, using kinematic GPS (global positioning system), in order to determine the medium-scale surface roughness, which is mainly controlled by the confluence of the tributaries with the main glacier tongue and the erosion activity of the meltwater streams
(Fig. 3). At Gore I, an extensive stake network has been installed for detailed investigation of the ablation conditions in the debris zone (Mihalcea and others, 2006). A pressure transducer drilled into the ice was used there also for continuous monitoring of the ice ablation (Bøggild and others, 2004). At the front of Baltoro glacier and Liligo glacier, laser scans at the beginning and the end of the fieldwork have been recorded in order to detect changes in snout geometry.

\section{THE BALTORO GLACIER SYSTEM}

Baltoro glacier is situated relatively far from larger settlements in the highest part of the eastern Karakoram. Despite rather difficult access, it is probably the most travelled to glacier in Pakistan because of the spectacular scenery and the existence of K2, Broad Peak and the Gasherbrum peaks (all $8000 \mathrm{~m}$ peaks) at its head (Fig. 1). The glacier was visited for the first time by Western explorers in the mid-19th century (probably A. Schlagintweit; H.H. Godwin Austen (Godwin Austen, 1864); W. Conway (Conway, 1893)).

Our analysis of the physiographical features of Baltoro glacier is based mainly on the map from Miyamori (2000), Advanced Spaceborne Thermal Emission and Reflection Radiometer (ASTER) and Landsat images of 1999, 2000 and 2001 and Shuttle Radar Topography Mission (SRTM) 90 m elevation data (2000), together with terrestrial imagery taken 


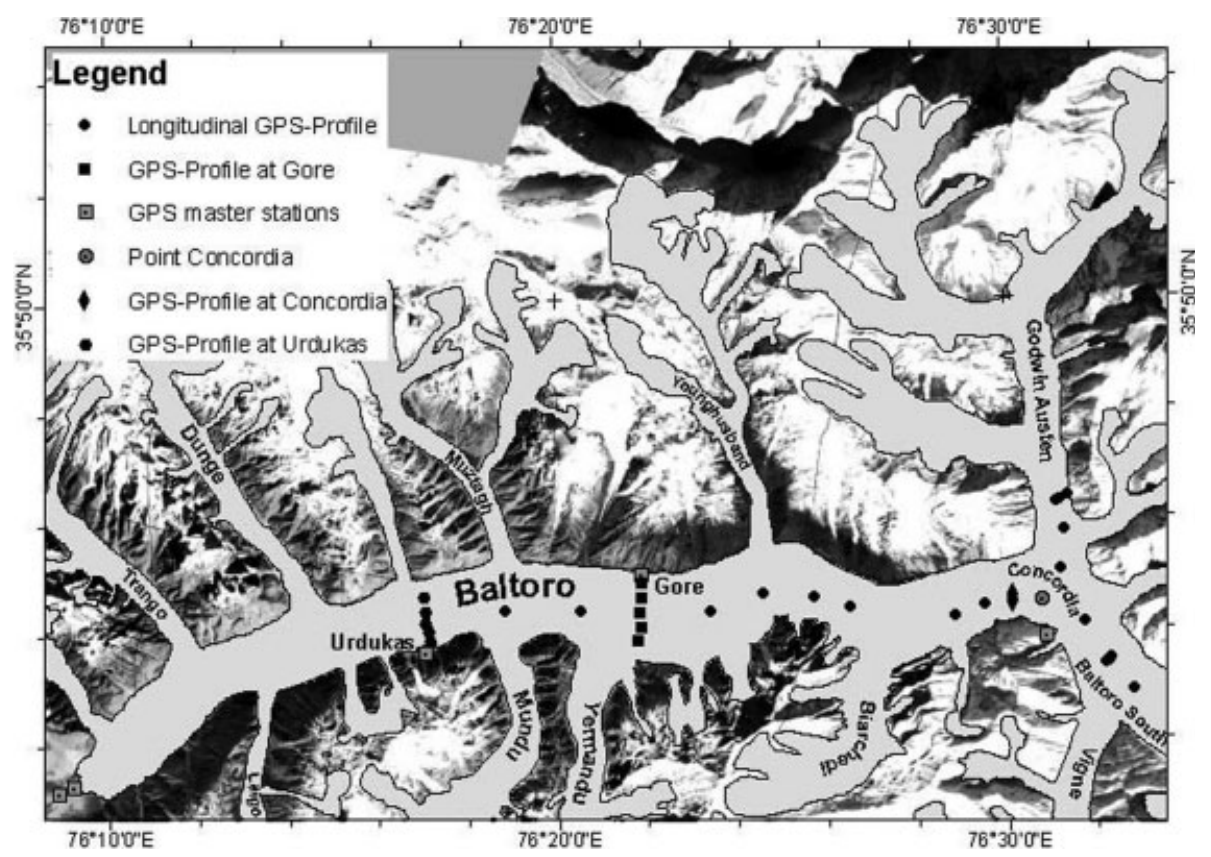

Fig. 2. The various measurement positions on Baltoro glacier. All stake positions shown have been measured twice with differential GPS. An orthoimage, calculated from ASTER scenes, is used as the base for the figure.

during the fieldwork. The satellite images have been orthorectified to the existing map and stored in the GIS in the local Universal Transverse Mercator (UTM) coordinate system. Surface classification, drainage basin calculations and the identification of the different glaciological units have been carried out afterwards.

The main glacier extends over a distance of $62 \mathrm{~km}$ from Conway Saddle at $6200 \mathrm{~m}$ to the glacier snout close to Paiju at $3400 \mathrm{~m}$ (Fig. 1). The average width is about $2.1 \mathrm{~km}$, reaching up to $3.1 \mathrm{~km}$ at Gore I just upstream of the confluence of Yermandu glacier with the main Baltoro tongue. With a mean slope of $3.9 \%$, it is a rather flat glacier compared with other glaciers of the Karakoram Range. In some areas (e.g. south of Concordia) the mean glacier surface rises only $21 \mathrm{~m}$ over a distance of $2 \mathrm{~km}$. On the other hand, the glacier surface is very rough perpendicular to the flow direction (Fig. 3). Surface undulations of $25 \mathrm{~m}$ over a horizontal distance of $140 \mathrm{~m}$ are common for many parts of the lower glacier. This is, on the one hand, due to the abundance of meltwater, forming large superficial meltwater streams. On the other hand, a rather high number of large tributary glaciers form a bundle of parallel ice bulges after merging

The surface classification was hampered by the fact that areas with fresh snow are oversaturated in the ASTER images. However, the bergschrund could be identified almost everywhere along the high-elevation basins. Therefore, only areas with clear features of glacier activity and firn fields below the bergschrund have been included in the glacier class (Fig. 4). Snow-covered 'non-glacier' areas which are in contact with the glacier and areas which are above the equilibrium line have been included in the accumulation area class, as long as they are draining into the accumulation area of the glacier class. This strategy has been followed because snow deposited on these highelevation slopes will most certainly either be redistributed by wind into the firn fields, or reach the glacier via avalanches. With this classification method, we find a glacier area of $524 \mathrm{~km}^{2}$, including all tributaries which are still connected with the main glacier. The additional accumulation area, classified as explained above, is $351 \mathrm{~km}^{2}$, whereas the total drainage basin of Baltoro glacier at Paiju comprises $1500 \mathrm{~km}^{2}$.

The fact that several large glaciers (Trango, Dunge, Muztagh, Younghusband, Mundu, Yermandu, Biarchedi, Godwin Austen, Vigne) contribute to the total glacier flow well below the equilibrium line makes it very difficult to generalize ice flux and other glacier parameters. One obvious location for the investigation of mass fluxes is the transect just downstream of the confluence of Baltoro south and Godwin Austen glaciers at Concordia. There, the two major glaciers join and at the same time they change their flow direction westward. An analysis of the ASTER images from 2001 has shown that the flowband of these two glaciers

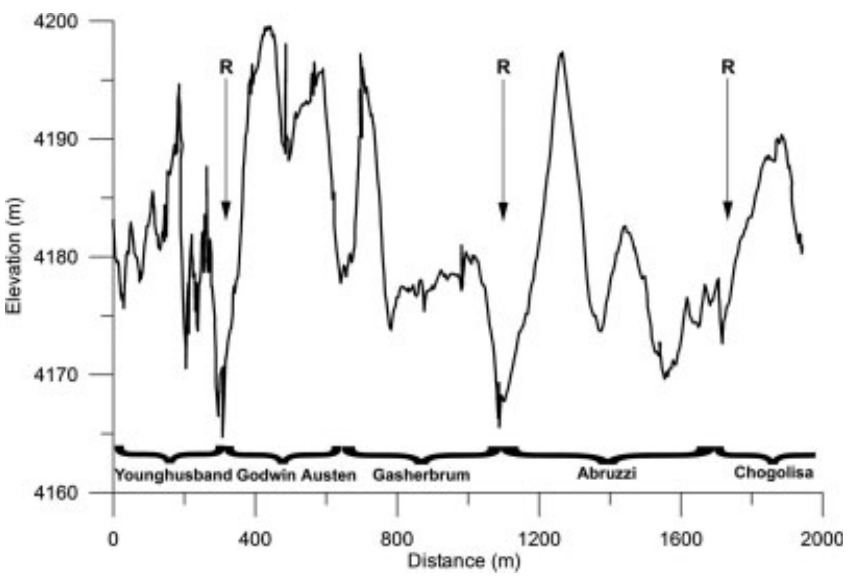

Fig. 3. Surface profile at the Gore I cross-profile, measured with differential GPS. The distance is given from the northern margin of the glacier. The contributions of the several tributary glaciers to the main Baltoro glacier are shown. In some of the depressions, major meltwater streams drain the surface of the glacier $(R)$. 


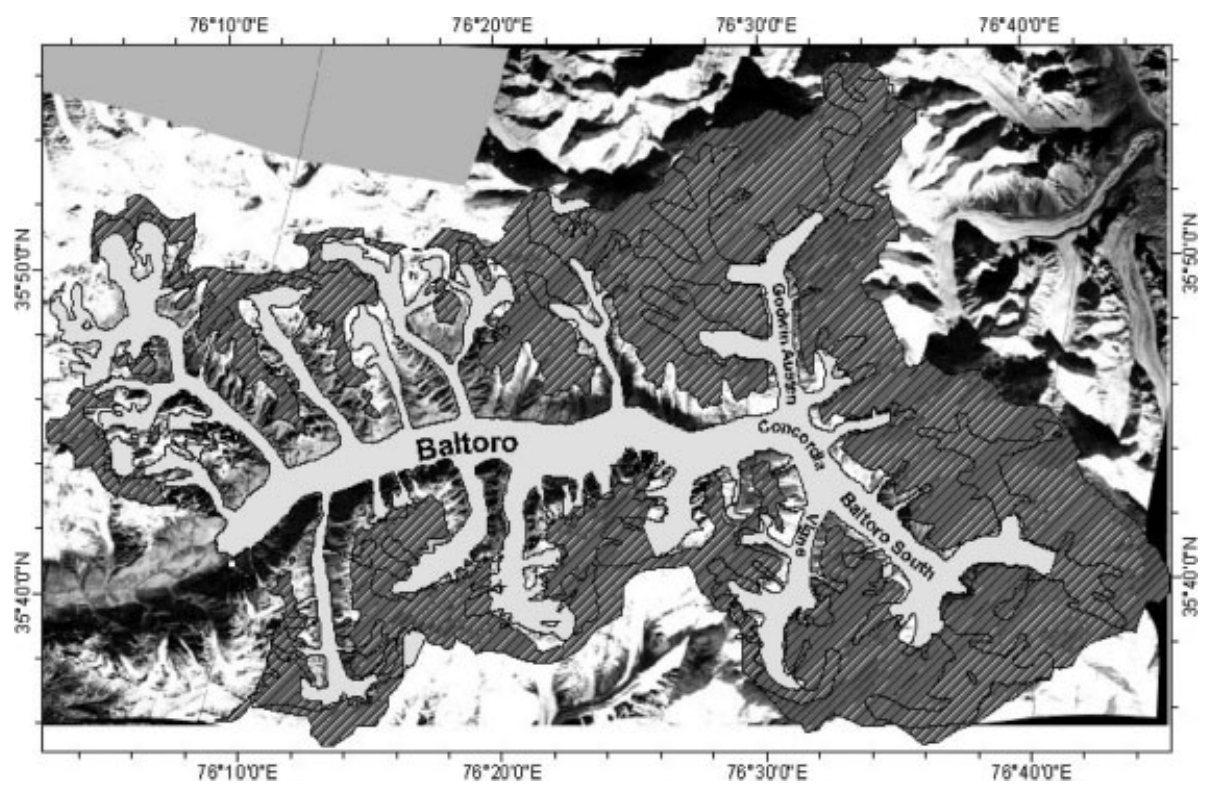

Fig. 4. Classification map of the Baltoro drainage basin. The area of the glacier proper is shown in light grey. The extent of the accumulation area (as discussed in the text) is indicated in striped dark grey. Note that only small areas of the glacier itself are situated in the accumulation area. The line separating the accumulation area from the ablation area forms the equilibrium line on the glacier.

together still represents $60 \%$ of the glacier width at Urdukas and $40 \%$ close to the glacier snout. Trango glacier, which enters the main glacier about $5 \mathrm{~km}$ upstream, forms another $45 \%$ of the glacier width at the snout. This fact indicates that observed variations of the glacier snout reflect changes in mass balance and ice dynamics of the main glacier only to some extent.

Baltoro glacier is a firn-kettle-type glacier (Wissmann, 1959) nourished from short high-elevation basins and avalanches from the steep valley slopes. Typically these firn basins are $5-8 \mathrm{~km}$ long, roughly $10 \%$ of the entire glacier length. The firn areas of the glacier (without slopes above the bergschrund) comprise $29 \%$ of the total glacier area.

No measurements to directly determine the equilibrium line on Baltoro glacier have ever been carried out in the field. However, theoretical calculations are available from Wissmann (1959) which are in good agreement with estimates from remote-sensing imagery. We therefore decided to use the values of Wissmann (1959), $5300 \mathrm{~m}$ for the Godwin Austen branch and $5500 \mathrm{~m}$ for Baltoro south, to determine the accumulation basins of Baltoro glacier. Snow accumulation in these areas, together with avalanche snow, is the only source of mass for the formation of the extensive glacier tongue.

An exact calculation of debris cover is rather difficult, but the analysis of the available satellite images enabled a statistical evaluation of the glacier surface conditions. Stretches of bare ice exposed at the glacier surface are usually short, because high debris loads and intensive melt lead to fast coverage with debris. On the main glacier the mean debris cover across the glacier is $>50 \%$ just a few kilometres from the equilibrium line. Downstream of about $5000 \mathrm{~m}$ the debris cover very soon increases to $70-90 \%$. In the area of Urdukas and further down, almost the entire glacier is covered by debris. Here, meltwater ponds, superficial streams and bare ice only account for a few per cent of the glacier area. In total, about $38 \%$ of the glacier area is debris-covered. As a consequence, about 33\% of the glacier consists of bare ice. The error of this analysis is $\pm 5 \%$.
The quantification of the debris thickness is even more difficult, due to the limited number of sample points and the large thickness variations even over short distances. Thickness measurements at more than 60 locations have been carried out, which show large variations even within small areas. Generally, debris thicknesses between $0.3 \mathrm{~m}$ and, in some places, $>1.5 \mathrm{~m}$ can be found at the snout. The thickness generally decreases upstream, but, even in the area close to K2 base camp, debris thicknesses of $20-30 \mathrm{~cm}$ can be found on the debris-covered flow bands. The grainsize also shows a very large variation all over the glacier, from sub-millimetre dust to boulders of a few metres diameter. The calculation of distributed ablation, therefore, is affected by considerable errors.

\section{GLACIER FLOW AND MASS TRANSPORT}

The Karakoram is strongly influenced by westerly winds. During the winter, cyclonic depressions originating in the Mediterranean and the Middle East dominate the local climate. During spring and early summer, irregular collapses of the Tibetan anticyclone will allow monsoonal air masses to penetrate into the Karakoram Range (Wake, 1989). Due to this strong influence of the jet stream on the high-elevation areas, precipitation at lowland stations cannot be used for estimates of rain and snowfall in the Baltoro area.

\section{Accumulation and ablation}

Several studies have found that annual precipitation exhibits a very large vertical gradient. At Biafo glacier, Wake (1989) found the maximum precipitation values in the elevation range $4900-5400 \mathrm{~m}$. For the Baltoro region the annual precipitation on the south slope of $\mathrm{K} 2$ shows rather small values of $200-150 \mathrm{~mm} \mathrm{a}^{-1}$ in the elevation range 2000 $3200 \mathrm{~m}$. From there, precipitation increases rapidly to $1600 \mathrm{~mm} \mathrm{a}^{-1}$ at $6100 \mathrm{~m}$ (Decheng, 1978). Above this elevation, a further increase to about $2500 \mathrm{~mm} \mathrm{a}^{-1}$ at an elevation of $8000 \mathrm{~m}$ is estimated by Decheng (1978) (Fig. 5). This means that for the relevant accumulation area of 


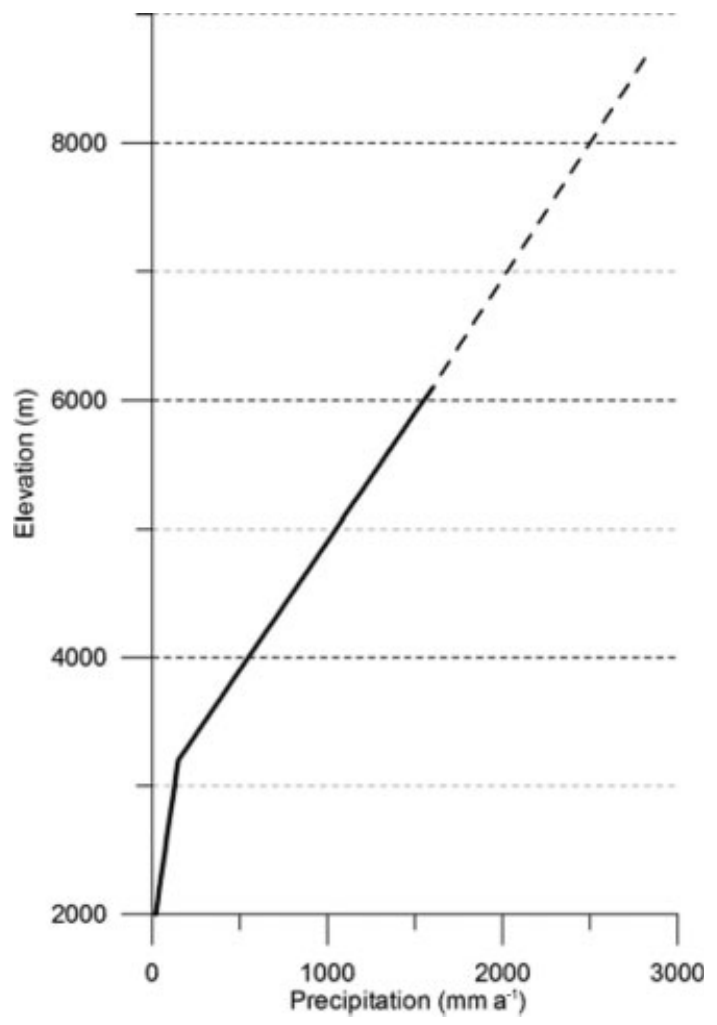

Fig. 5. Vertical profile of precipitation in the Baltoro region, reconstructed from Decheng (1978) and Wake (1989). Values above $6100 \mathrm{~m}$ are only estimates.

Baltoro glacier, which lies above $5300 \mathrm{~m}$ for the Godwin Austen region and $5500 \mathrm{~m}$ for the Baltoro south region (Wissmann, 1959), the mean annual precipitation is about $1600 \mathrm{~mm} \mathrm{a}^{-1}$.

At this elevation, precipitation in almost all cases is deposited as snow. During the period of temperature measurements in summer 2004 (8 July-4 August), the mean daytime temperature (0600-1800 h) at K2 base camp was $2.1^{\circ} \mathrm{C}$, which corresponds to a mean daytime temperature close to the freezing point at $5400 \mathrm{~m}$. In average the entire drainage area above the equilibrium line contributes to accumulation of Baltoro glacier. Ice-free areas and icecovered areas which are not directly connected to the main glacier system provide mass through avalanches or wind redistribution. Run-off of meltwater from these highelevation regions is restricted to very few days during the summer months and affects only a few per cent of the total accumulation. However, this effect has been taken into account via a simple degree-day approach in the calculation of the net accumulation. Sublimation plays an important role in high-altitude and dry regions. Due to the lack of appropriate data, an estimated constant value of $-250 \mathrm{~mm} \mathrm{a}^{-1}$ for the firn areas has been accounted for in the mass-balance calculations (according to investigations of Wagnon and others, 2003; Mölg and Hardy, 2004).

In contrast to the $29 \%$ of firn area for the glacier itself, the accumulation-area ratio (AAR) is $40 \%$ if the contributing high slopes are included in the analysis. The true AAR therefore lies between these limits of $29 \%$ and $40 \%$. As mentioned above, the cross-section at Concordia is a natural location for the computation of mass fluxes. The area upstream of Concordia represents, after all, $56 \%$ of the entire glacier area, including the contributing accumulation

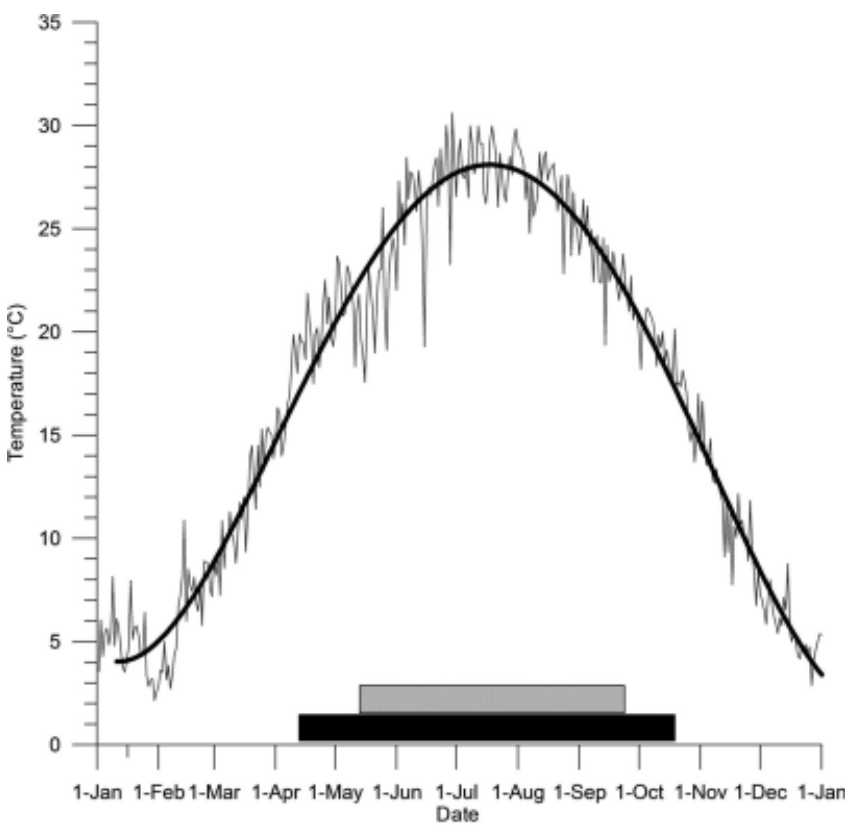

Fig. 6. Annual temperature variation for Srinagar, Kashmir, calculated as daily mean temperatures from 1972 to 1982 (thick black line: running 30 day mean). The general melt period at Baltoro is shown as a black bar, and the intense melting period is indicated by a light grey bar.

area. There, information about ice velocities and estimates of ice thickness are also available (Desio and others, 1961).

Considering all the points mentioned above, balance calculations have been carried out for the part of Baltoro glacier upstream of Concordia. The vertical precipitation profile, the area/elevation distribution and the prevailing climatic conditions have been used to determine the net accumulation above the equilibrium line, which resulted in a mass flux of $0.51 \mathrm{~km}^{3} \mathrm{a}^{-1}$ for this part of the glacier. For this purpose, precipitation values from Figure 5 have been converted to net accumulation and then multiplied by the area of the corresponding elevation bands. For the conversion it was assumed that for elevations with degree-day sums of 0 , net accumulation equals $100 \%$ of precipitation (for Baltoro glacier this is the case above $5700 \mathrm{~m}$, using extrapolated temperature data from Srinagar; Fig. 6). Net accumulation then reduces linearly to $0 \%$ of the precipitation value at the equilibrium line. Ablation measurements (Mihalcea and others, 2006) at Concordia and further upstream provided the basis for calculating the net ablation. Using the determined mean lapse rate and extrapolating the temperature data over the entire ablation period by using long-term temperature data from Srinagar (Fig. 6), the estimated net ablation for the specified area is $-0.17 \mathrm{~km}^{3} \mathrm{a}^{-1}$. The Srinagar station, $230 \mathrm{~km}$ from Urdukas at 1585 ma.s.l. in the Indian part of Kashmir, is the only place with available long-term temperature measurements. Climatically this station is also influenced by the Indian monsoon system. This allows us to transfer temperature data via a lapse rate, determined from overlapping measurement periods, to the different locations on Baltoro glacier. Obviously, there are considerable errors due to the lack of long-term local data. Nevertheless, the possible variations should not exceed $30 \%$. As a result, the net balance above Concordia is $0.34 \pm 0.10 \mathrm{~km}^{3} \mathrm{a}^{-1}$. 

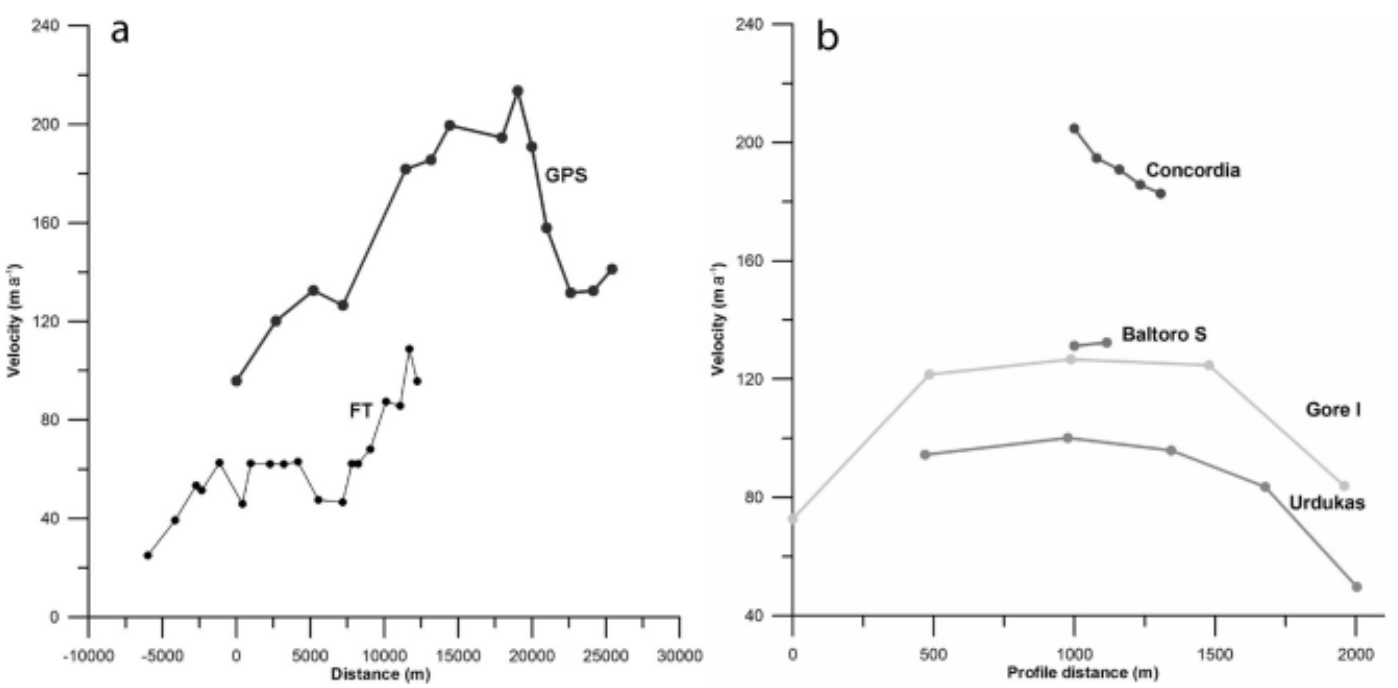

Fig. 7. Surface velocities of the glacier based on differential GPS measurements and feature tracking of satellite images. (a) The velocities along the longitudinal profile determined by repeated, short-term GPS measurements. The 'real' annual mean velocities from the analysis of the satellite images are shown as the lower curve. The distance along the glacier originates at the Urdukas cross-profile. (b) The velocities of the cross-profiles based on the summer velocities from GPS measurements. The profile distance is centred to the glacier width at Gore I.

\section{Ice velocity}

The surface velocity has been measured by differential GPS at 32 stakes distributed over the glacier from Urdukas up to about $4800 \mathrm{~m}$. The base stations for the measurements have been placed on firm ground at the glacier margin (at Urdukas, Gore I and Concordia). The observation periods range between 1 and 11 days, depending on the reoccupation of the stake on the journey down-glacier. The velocity profiles show some interesting features related to the complex ice flow of the glacier (Fig. 7). On an alpine glacier with constant bed geometry, maximum velocities can be expected close to the equilibrium line (Paterson, 1994). For Baltoro glacier the maximum surface velocity, $58.5 \pm 0.4 \mathrm{~cm} \mathrm{~d}^{-1}$, has been observed just downstream of the Concordia cross-profile. This equates to an annual velocity of $214 \mathrm{~m} \mathrm{a}^{-1}$ for the 3 days of observations. On Baltoro south, the velocity decreases to $131 \mathrm{~m} \mathrm{a}^{-1}, 3.6 \mathrm{~km}$ upstream from the velocity maximum. The velocities on Godwin Austen Glacier are of similar magnitude $\left(120 \mathrm{~m} \mathrm{a}^{-1}\right)$. The reason for this increase in velocity is the strongly convergent flow when the two glaciers merge and enter the main valley. An analysis of the flowband widths reveals that the ice flux is almost constant (if a constant ice thickness is assumed along the $3.6 \mathrm{~km}$ ). Following the glacier downstream, the velocities decrease to values around $120 \mathrm{~m} \mathrm{a}^{-1}$ at Gore I. The observed speed-up below Gore $\mathrm{I}$ is due to the inflow of Yermandu glacier which drains a major basin below Masherbrum $(7821 \mathrm{~m})$. From there the velocity drops again rather rapidly to $85 \mathrm{~m} \mathrm{a}^{-1}$ at Urdukas. For a similar velocity gradient further downstream, the velocities should reach close to zero about $4 \mathrm{~km}$ before the glacier front. However, in this region the rather active Trango glacier enters Baltoro glacier, which could result in higher ice velocities in this frontal part.

The cross-profiles of the surface velocity (Fig. 7) show that the transverse gradient is rather small. At Gore I, the outer stakes of the cross-profile are only a few hundred metres from the glacier margin. There, the ice velocity is still $70 \%$ of the centre velocity. Similar conditions exist at Urdukas, whereas the other profiles are too short for an analysis of the transverse velocity gradient.

So far, only the velocities from the GPS measurements have been discussed. The fieldwork was carried out during the first half of the main melt period (Fig. 6). This means abundant meltwater enhances ice flow and results in higher velocities than the mean annual velocities. In order to quantify the differences between summer velocities and

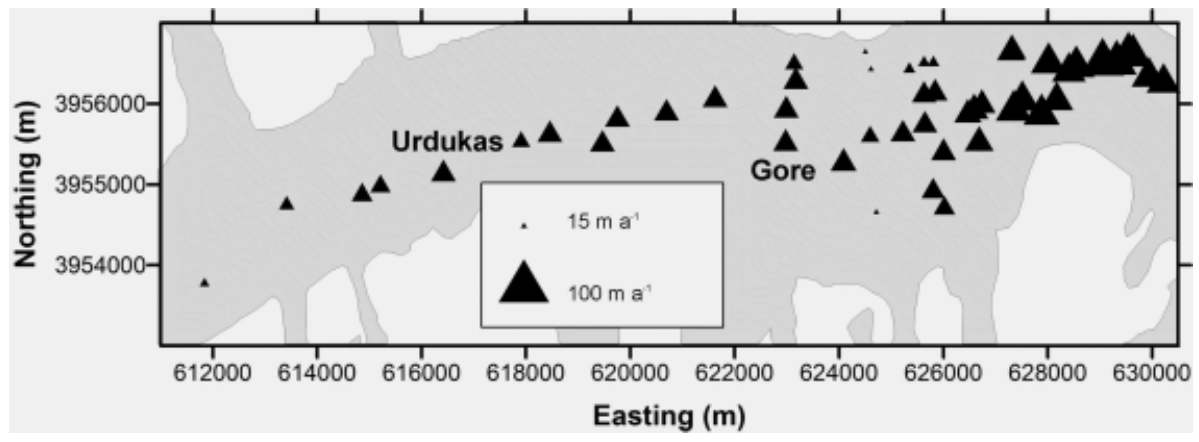

Fig. 8. Result of the feature-tracking analysis of the central part of the ablation zone. The triangles are proportional to the ice surface velocity and provide a qualitative impression of the velocity distribution over the glacier surface. The very small values upstream of Gore I are measured very close to the glacier margin. 


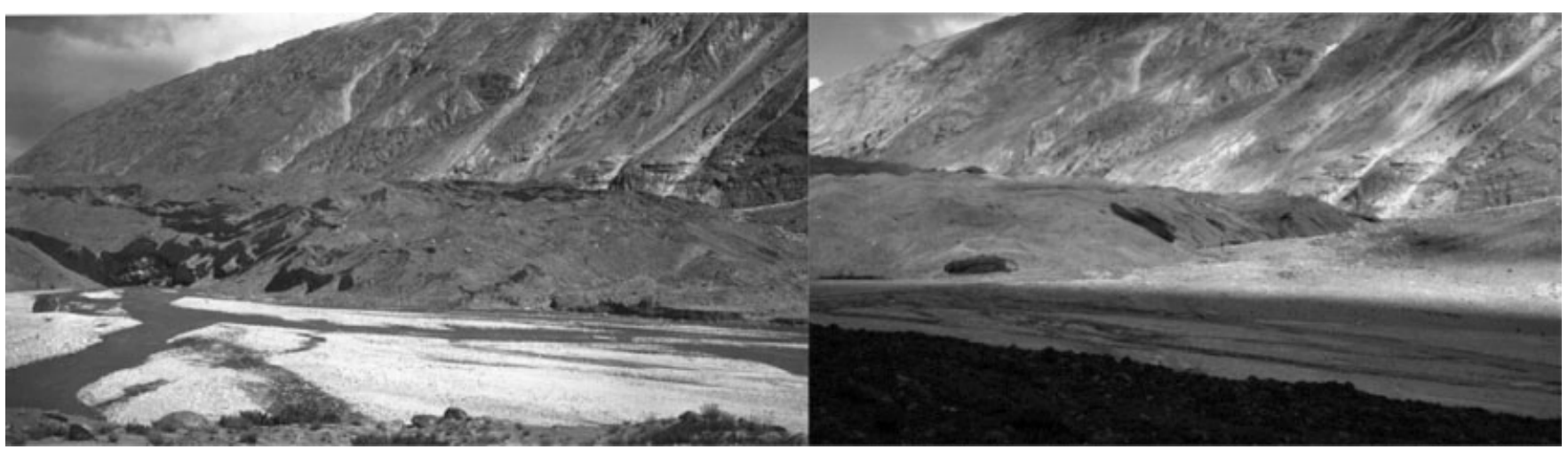

Fig. 9. Comparison of photographs of the southern part of the glacier snout, with flow from left to right. The left photograph was taken in 1954, the right one in 2004.

annual mean velocities, the orthorectified satellite images have been used. Landsat and ASTER have an optical resolution of the same order of magnitude. This means they can be used together for tracking stable features on the glacier. 'Ice sails', single mounds of clean ice of 5-20 m height, occur over a large part of the ablation area. In the region of Liligo and up to a few kilometres upstream of Gore I, individual ice sails can clearly be identified on the otherwise debris-covered glacier. Tracking of these ice sails over a time-span of 2 years resulted in an annual velocity map for the central part of the ablation zone (Fig. 8). For the identification of the ice-sail position the brightness distribution across the ice sails has been analyzed. With this method the resulting error in surface velocity is about $\pm 20 \mathrm{~m} \mathrm{a}^{-1}$. Interpolating these values onto the longitudinal GPS profile (GPS) of Figure 7a results in the lower velocity profile (FT). The two different velocity measurements confirm that the summer velocities are a factor of about two higher than the annual mean velocities, at least for the main part of the ablation zone, up to Concordia.

During the 1954 expedition, gravity measurements were carried out to determine the ice thickness (Desio and others, 1961). For Concordia a value of $858 \pm 50 \mathrm{~m}$ is reported. The analysis of the gravity data is based on an elliptical glacier bed, which resulted in a cross-sectional area of the glacier of $3.86 \pm 0.7 \mathrm{~km}^{2}$ for that case. The summer velocity for 2004 was found to be $190 \mathrm{ma}^{-1}$, whereas the annual mean velocity was extrapolated from the gradient in the differences between summer velocity and annual mean velocity further downstream. The resulting annual mean velocity at Concordia, therefore, is $95 \pm 20 \mathrm{~m} \mathrm{a}^{-1}$. The strong annual velocity variations indicate that basal sliding plays a major part in the ice transport of Baltoro glacier. Thus the mean ice velocity at depth was assumed to be $95 \%$ of the surface velocity (Paterson, 1994). With these assumptions the resulting flux through the cross-section of Concordia is $0.35 \pm 0.13 \mathrm{~km}^{3} \mathrm{a}^{-1}$. A comparison with the estimated mass input from the upper part of the glacier shows excellent agreement. However, the uncertainties are rather large (on the order of $35 \%$ ), which could easily obscure an imbalance in the glacier mass balance.

\section{HISTORICAL FLUCTUATIONS}

As mentioned above, Baltoro glacier has been visited for a long time. Thus, we have a long history of glacier photography. Two examples of the changes in glacier characteristics are discussed here.

The tongue of Baltoro glacier has formed from two contributions: Trango glacier, which occupies the northern part of the valley, and the flowband of the main Baltoro glacier, which flows down from Concordia and covers the southern part of the valley.

A comparison can be made between images of the state of this southern part of the glacier from 1954 and 2004 (Fig. 9). During this 50 year time-span, the glacier tongue has receded about $200 \mathrm{~m}$ and the snout has become flatter. It should be noted that small changes occurred in the snout morphology, and, in particular, the main outflow river changed its position; it is now located in the northern sector of the glacier terminus. However, in an unpublished picture by A. Desio in 1929, the entire glacier snout looks almost identical to the modern one. An analysis of the measurements carried out during the last 91 years shows that there is no clear trend of recession or advance.

The terminus variations collected since the beginning of the 20th century confirm the glacier snout behaviour demonstrated by the photo comparison. In Table 1 the distances between 'Desio boulder' and the glacier snout of Baltoro glacier are shown. 'Desio boulder' is an erratic block

Table 1. Distances measured from 'Desio boulder' (3366 m a.s.I.) to the glacier snout by various authors in the past 91 years. Our two measurements have been selected according to the azimuth values of earlier observations

Source

Year Distance from Azimuth from glacier snout true north

$\mathrm{m}$

\begin{tabular}{lccc}
\hline Dainelli, 1928 & 1913 & 80 & 70 \\
Savoia and Desio, 1936 & 1929 & 18 & 70 \\
$\begin{array}{l}\text { Desio and others, 1961 } \\
\text { Smiraglia, 1987 }\end{array}$ & 1954 & 296 & not reported \\
$\begin{array}{l}\text { F. Maragnoli, personal } \\
\quad \text { communication }\end{array}$ & 1985 & 172 & 57 \\
$\begin{array}{l}\text { A. Rampini, personal } \\
\quad \text { Communication }\end{array}$ & 1990 & 160 & 57 \\
$\begin{array}{l}\text { Pecci and Smiraglia, 2000 } \\
\text { This study }\end{array}$ & 1997 & 171.4 & 57 \\
$\quad$ This study & 2004 & 145 & 70 \\
& 2004 & 140 & 70 \\
\end{tabular}



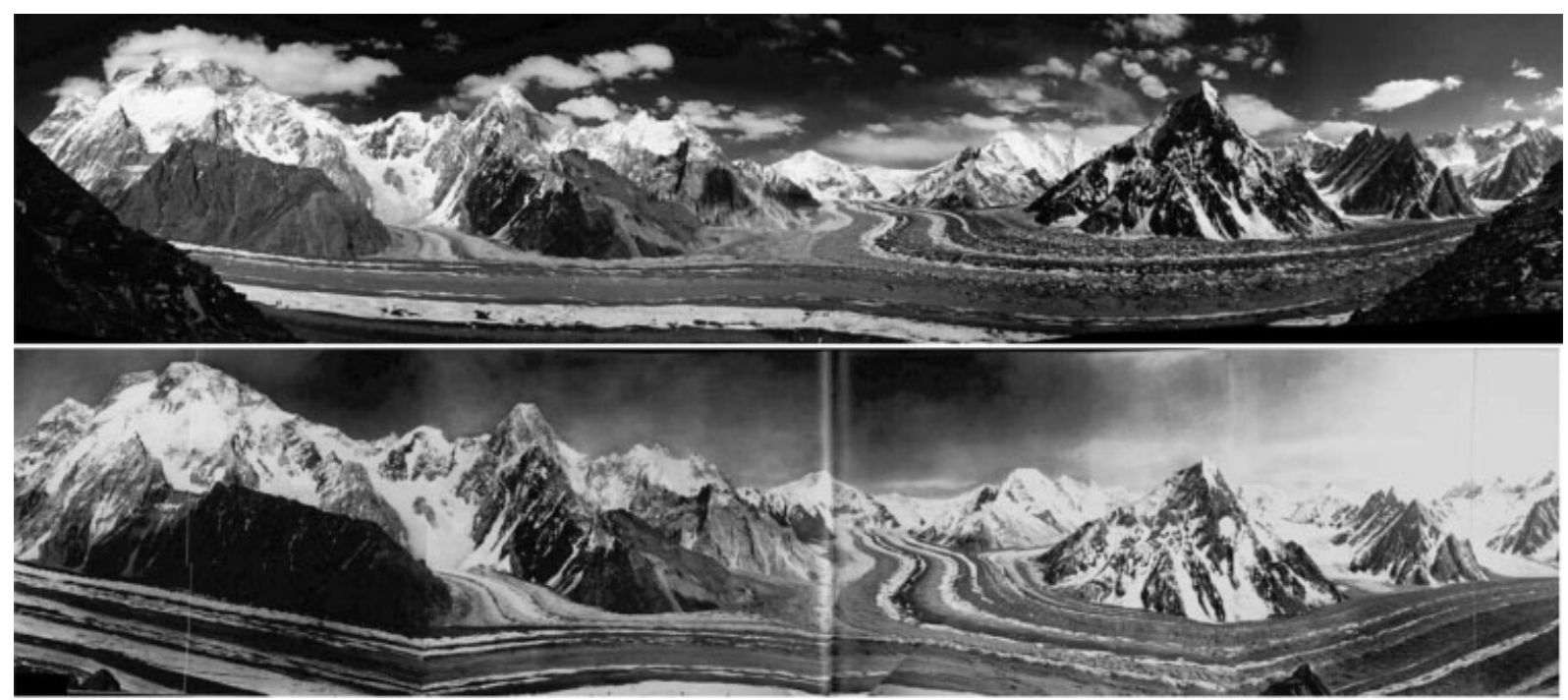

Fig. 10. Comparison of the situation at Concordia in 1909 (V. Sella in De Filippi, 1912, lower image) and 2004 (taken by C. Mayer, upper image). Both pictures were taken from the slope below Marble Peak.

at 3366 ma.s.I., named after A. Desio, who used it as a reference point. These data confirm that the glacier terminus experienced only limited fluctuations (cumulated value $-65 \mathrm{~m}$ over the period 1913-2004 with azimuth $70^{\circ}$ ), reflecting a quite stable snout position.

For Concordia, there exists one of the famous panoramas of V. Sella from 1909. In 2004 we tried to take a series of photographs from the same position. Due to lack of time, we could not reach the same elevation as Sella 95 years before. The panorama from 2004 is taken from about $200 \mathrm{~m}$ below the 1909 position (Fig. 10). Careful analysis of the images has shown that the elevation differences of the glacier surface in this time-span are $<40 \mathrm{~m}$. Along almost the entire glacier margin which is identifiable on the images, the ice is more or less at the same level as 95 years ago. Some minor changes are discernible, but their magnitude is minor compared to changes of other mountain glaciers, especially in the Alps, where glaciers lost about $30 \%$ of their surface area in the same time-span (Beniston, 2003). The reason for such limited changes on Baltoro is surely the debris cover present on its surface. This reduces the surface ablation and thus slows down the glacier recession.

The observations of changes in the snout position and variations in the glacier elevation at Concordia lead to the conclusion that the extent and ice volume of Baltoro glacier showed only minor changes during the last century.

\section{CONCLUSIONS}

The analysis of data from extensive field measurements and satellite data from Baltoro glacier in the Karakoram revealed the physical characteristics of this vast glacier system. The glacier is constituted of several major tributary glaciers, which complicates conclusions on the overall mass balance. The upper main part of the glacier, upstream of Concordia, represents the major mass fluxes and dominates ice dynamics down to the glacier snout. Most of the tributary glaciers are merged almost completely shortly after the inflow into the main branch.

For the upper Baltoro (upstream of Concordia), the mass balance is very likely close to zero. This is surprising, because this part of the glacier shows the least debris cover on the ablation part and therefore should be affected first by climatic variations. Probably this stability is due to the extensive and very high accumulation area which, to a large extent, is not dynamically linked with the glacier. Accumulation is mainly deposited by wind redistribution and avalanches onto the glacierized areas.

The velocities show a distinct difference between summer and winter. The summer velocities are up to twice the annual velocities. This demonstrates clearly that the ice flow of Baltoro glacier is dominated by basal sliding, at least during the melt period. The large ice thicknesses, up to $900 \mathrm{~m}$, very probably ensure the existence of temperate conditions at the glacier base during the winter.

The analysis of historical and modern photographs and measurements of the glacier tongue fluctuations confirm the indications that Baltoro glacier was rather stable during the last 100 years. In spite of the surge-type behaviour of neighbouring glaciers (Diolaiuti and others, 2003b) and a worldwide recession of alpine glaciers (Beniston, 2003), this glacier seems to be protected by its extensive debris cover, which reaches almost up to the accumulation area. Variations of the lower part of Baltoro are now, and will also be in the future, most probably due to the reaction of the tributary glaciers to changes in climate. These glaciers present much smaller accumulation areas at decidedly lower elevations.

\section{ACKNOWLEDGEMENTS}

Fieldwork for these investigations has kindly been enabled by the Ev-K2-CNR project 'Scientific and Technological Research in Himalaya and Karakorum' in the framework of the scientific-mountaineering expedition 'K2 2004 50 years later'. Coordination between the Italian and German researchers has been supported by the DAAD-Vigoni project D/04/47058. We also express sincere thanks to A. Tamburini, L. Bonetti and G. Peretti for assisting the fieldwork, and E. Vuillermoz for support in automatic weather station management and meteorological data processing. We are especially grateful to all the local porters and our guide Ali for excellent support. 


\section{REFERENCES}

Batura Glacier Investigation Group. 1979. The Batura Glacier in the Karakoram Mountains and its variations. Sci. Sin., 22(8), 958-974.

Beniston, M. 2003. Climatic change in mountainous regions - a review of possible impacts. Climatic Change, 59, 5-31.

Bøggild, C.E., O.B. Olesen, A.P. Ahlstrøm and P. Jørgensen. 2004. Automatic glacier ablation measurements using pressure transducers. J. Glaciol., 50(169), 303-304.

Conway, W.M. 1893. Exploration in the Mustagh Mountains. Geogr. J., 2, 27-32.

Dainelli, G. and O. Marinelli. 1928. Relazione scientifiche della Spedizione Italiana de Filippi, nell'Himalaia, Caracorum e Turchestan Cinese (1913-1914). Serie II: Risultati geologici e geografici. Vol. IV. Bologna, Zanichelli.

De Filippi, F. 1912. La spedizione di S.A.R. il Principe Luigi Amedeo di Savoia Duca degli Abruzzi nel Karakorum e nell'Himalaya occidentale (1909). Bologna, Zanichelli.

Decheng, M. 1978. The map of snow mountains in China, K2 (Mount Quogori). Lanzhou, Chinese Academy of Sciences. Lanzhou Institute of Glaciology and Geocryology.

Desio, A., A. Marussi and M. Caputo. 1961. Glaciological research of the Italian Karakorum Expedition 1953-1955. IASH Publ. 52 (General Assembly of Helsinki 1960 - Snow and Ice), 224-232.

Ding, Y. 1992. Some glacio-micrometeorological features on the north side of Mount Qogir (K2), Karakorum Mountains. Ann. Glaciol., 16, 67-72.

Diolaiuti, G., C. D'Agata and C. Smiraglia. 2003a. Belvedere Glacier, Monte Rosa, Italian Alps: tongue thickness and volume variations in the second half of the 20th century. Arct. Antarct. Alp. Res., 35(2), 255-263.

Diolaiuti, G., M. Pecci and C. Smiraglia. 2003b. Liligo Glacier, Karakoram, Pakistan: a reconstruction of the recent history of a surge-type glacier. Ann. Glaciol., 36, 168-172.

Godwin Austen, H.H. 1864. On the glaciers of the Mustagh Range. J. R. Geogr. Soc., 34, 19-56.

Hagg, W. and L. Braun. 2005. The influence of glacier retreat on water yield from high mountain areas: comparison of Alps and central Asia. In De Jong, C., R. Ranzi and D. Collins, eds. Climate and hydrology in mountain areas. Chicester, Wiley \& Sons, 263-275.
Hewitt, K., C.P. Wake, G.J. Young and C. David. 1989. Hydrological investigations at Biafo Glacier, Karakorum Range, Himalaya; an important source of water for the Indus River. Ann. Glaciol., 13, 103-108.

Konovalov, V.G. 1997. The hydrological regime of Pamir-Alai glaciers. Z. Gletscherkd. Glazialgeol., 33(2), 125-131.

Mattson, L.E. and J.S. Gardner. 1989. Energy exchange and ablation rates on the debris-covered Rakhiot Glacier, Pakistan. Z. Gletscherkd. Glazialgeol., 25(1), 17-32.

Mihalcea, C., C. Mayer, G. Diolaiuti, A. Lambrecht, C. Smiraglia and G. Tartari. 2006. Ice ablation and meteorological conditions on the debris-covered area of Baltoro glacier, Karakoram, Pakistan. Ann. Glaciol., 43 (see paper in this volume).

Miyamori, T. 2000. Baltoro Glacier and Khapulu. (Mountaineering maps of the Karakorum and Hindu-Kush, No. 10.) Kyoto, Nakanishiya Shuppan Co. Ltd.

Mölg, T. and D.R. Hardy. 2004. Ablation and associated energy balance of a horizontal glacier surface on Kilimanjaro. J. Geophys. Res., 109(D16), D16104. (10.1029/2003JD004338.)

Paterson, W.S.B. 1994. The physics of glaciers. Third edition. Oxford, etc., Elsevier.

Pecci, M. and C. Smiraglia. 2000. Advance and retreat phases of the Karakorum glaciers during the 20th century: case studies in Braldo Valley (Pakistan). Geografía Física e Dinámica Quaternaria, 23(1), 73-85.

Savoia-Aosta, A. and A. Desio. 1936. Spedizione geografica italiana al Karakoram (1929): storia del viaggio e risultati geografici. Milan, Bertarelli.

Smiraglia, C. 1987. Baltistan, le ricerche geografico-fisiche. L'Universo, 57(5), 583-619.

Spoleto, H.R.H. 1930. The Italian expedition to Karakorum in 1929. Geogr. J., 75(5), 385-401.

Wagnon, P., J.E. Sicart, E. Berthier and J.P. Chazarin. 2003. Wintertime high-altitude surface energy balance of a Bolivian glacier, Illimani, $6340 \mathrm{~m}$ above sea level. J. Geophys. Res., 108(D6), 4177. (10.1029/2002JD002088.)

Wake, C.P. 1989. Glaciochemical investigations as a tool for determining the spatial and seasonal variation of snow accumulation in the central Karakorum, northern Pakistan. Ann. Glaciol., 13, 279-284.

Wissmann, H. von. 1959. Die heutige Vergletscherung und Schneegrenze in Hochasien. Akad. Wiss. Lit. Mainz, Abh. Math.-Naturw. Kl., 14, 1101-1407. 